\title{
Conspicuous Plumage Does Not Increase Predation Risk: A Continent-Wide Test Using Model Songbirds
}

\author{
Kristal E. Cain, ${ }^{1,2, \star}$ Michelle L. Hall, ${ }^{3}$ Illiana Medina, ${ }^{1}$ Ana V. Leitao, ${ }^{3}$ Kaspar Delhey, ${ }^{4}$ \\ Lyanne Brouwer, ${ }^{1,5}$ Anne Peters, ${ }^{4}$ Stephen Pruett-Jones, ${ }^{6}$ Michael S. Webster, \\ Naomi E. Langmore, ${ }^{1}$ and Raoul A. Mulder ${ }^{3}$
}

1. Research School of Biology, Australian National University, Canberra, Australian Capital Territory 2600, Australia; 2. School of Biological Sciences, University of Auckland, Auckland, 1010 New Zealand; 3. School of BioSciences, University of Melbourne, Parkville, Victoria 3010, Australia; 4. School of Biological Sciences, Monash University, Clayton, Victoria 3800, Australia; 5. Department of Animal Ecology, Netherlands Institute of Ecology NIOO-KNAW, 6700 AB Wageningen, The Netherlands; 6. Department of Ecology and Evolution, University of Chicago, Chicago, Illinois 60637; 7. College of Agriculture and Life Sciences, Neurobiology and Behavior, Cornell University, Ithaca, New York 14853

Submitted January 10, 2018; Accepted September 24, 2018; Electronically published January 23, 2019

Online enhancement: appendix.

AвSTRACT: The forces shaping female plumage color have long been debated but remain unresolved. Females may benefit from conspicuous colors but are also expected to suffer costs. Predation is one potential cost, but few studies have explicitly investigated the relationship between predation risk and coloration. The fairy-wrens show pronounced variation in female coloration and reside in a wide variety of habitats across Australasia. Species with more conspicuous females are found in denser habitats, suggesting that conspicuousness in open habitat increases vulnerability to predators. To test this, we measured attack rates on 3-D-printed models mimicking conspicuously colored males and females and dull females in eight different fairy-wren habitats across Australia. Attack rates were higher in open habitats and at higher latitudes. Contrary to our predictions, dull female models were attacked at similar rates to the conspicuous models. Further, the probability of attack in open habitats increased more for both types of female models than for the conspicuous male model. Across models, the degree of contrast (chromatic and achromatic) to environmental backgrounds was unrelated to predation rate. These findings do not support the long-standing hypothesis that conspicuous plumage, in isolation, is costly due to increased attraction of predators. Our results indicate that conspicuousness interacts with other factors in driving the evolution of plumage coloration.

Keywords: color, plumage, predation risk, sexual dichromatism, $M a-$ lurus, habitat, contrast.

\footnotetext{
* Corresponding author; email: kristalcain@gmail.com.

ORCIDs: Cain, http://orcid.org/0000-0002-6908-7015; Hall, https://orcid.org /0000-0002-1263-8314; Medina, http://orcid.org/0000-0002-1021-5035; Leitao, http://orcid.org/0000-0001-5367-9158; Delhey, http://orcid.org/0000-0001-5190 -5406; Brouwer, http://orcid.org/0000-0001-6728-4851; Peters, https://orcid.org /0000-0001-8071-0560; Pruett-Jones, https://orcid.org/0000-0002-1263-8314; Webster, http://orcid.org/0000-0001-7585-4578; Langmore, https://orcid.org/0000-0003 -3368-6697; Mulder, http://orcid.org/0000-0002-2710-0947.
}

Am. Nat. 2019. Vol. 193, pp. 000-000. (C) 2019 by The University of Chicago. 0003-0147/2019/19303-58188\$15.00. All rights reserved. DOI: $10.1086 / 701632$
Introduction

The function of bird coloration and the evolutionary forces that shape its variation are a classic topic in evolutionary biology, dating back to debates between Darwin and Wallace (Darwin 1872; Wallace 1891; Amundsen 2000b). Conspicuous coloration is generally regarded as costly in terms of natural selection, increasing predation risk and requiring energy to produce or maintain (Andersson 1994; Burns 1998; Dale et al. 2015; Dunn et al. 2015). Despite these costs, males often benefit from conspicuous colors due to sexual selection (Andersson 1994). In contrast, females rarely experience strong mating competition. As a consequence, the occurrence of conspicuous plumage in females has historically been considered a function of their shared genetic architecture, a nonfunctional by-product of strong selection on males leading to a correlated response in females (Lande 1980; Amundsen 2000b). However, recent work has shown that conspicuous colors (along with song and intrasexual aggression) can be beneficial for females, functioning in the context of male mate choice and female-female competition for reproductive resources (Amundsen 2000a; Tobias et al. 2012; Cain and Rosvall 2014; Dale et al. 2015). Further, phylogenetic work has shown that changes in species coloration and sexual dichromatism are typically due to gains or losses of conspicuous colors in females rather than changes in male coloration (Irwin 1994; Price and Birch 1996; Burns 1998; Dale et al. 2015; Simpson et al. 2015).

Given that selection is actively shaping female plumage and that females often benefit from conspicuous colors, it appears that the more pertinent question is not why females are sometimes colorful but why so many females are dull. The predominant explanation is that conspicuous coloration is costly because it increases detectability by predators 
and thus predation risk. This explanation has found support in a variety of taxa; conspicuously colored or contrasting prey often attract more predator attention (Godin and McDonough 2003; Huhta et al. 2003; Stuart-Fox et al. 2003; Vignieri et al. 2010). However, the pattern is not clear in birds. Though some comparative studies suggest that conspicuous plumage can increase predation risk at the nest (Promislow et al. 1992, 1994; Martin 1995; Burns 1998; Dunn et al. 2015), a recent broadscale examination of songbird dichromatism found that sex differences in color were unrelated to nest attendance (Matysioková et al. 2017). Further, there are few empirical studies that show a direct increase in actual predation risk for adult birds due to more conspicuous plumage (Caldwell 1986; Huhta et al. 2003). In fact, many studies report the opposite pattern, that is, that predators often preferentially attack cryptic rather than conspicuous birds (Götmark 1992, 1994; Götmark and Unger 1994; Götmark and Hohlfält 1995; Ruiz-Rodríguez et al. 2013). This may be due to behavioral differences; during the breeding season, females (which tend to be more cryptic) have greater caloric needs and may be more willing to take risks (Götmark and Unger 1994; Powolny et al. 2014), and dull plumaged birds of both sexes may be less vigilant (McQueen et al. 2017). Alternatively, predator preferences for cryptic individuals may stem from conspicuously colored individuals being more difficult to catch (the unprofitable prey hypothesis; Baker and Parker 1979). These conflicting patterns suggest that this relationship may be less straightforward than is often assumed and that explicit tests of the relationship between color and predation risk are required.

Predator pressure is the end result of a combination of many factors such as detectability (conspicuousness against background), habitat structure (which may affect detectability), predator density, and predator type (some predators rely more heavily on visual cues than others; Endler 1978). Thus, the costs of conspicuous plumage are likely to vary across habitats; for example, conspicuous colors may be more costly in open habitats as conspicuousness increases the risk of detection by a visual predator. Further, though background color plays an important role in how detectable an animal is (Endler 1978), previous studies examining the role of plumage conspicuousness in predation did not account for how conspicuous a prey item is in different backgrounds. Similarly, latitude is often strongly associated with predation pressure (Díaz et al. 2013; Roslin et al. 2017), but there are many potential mechanisms underlying that relationship. For instance, for model caterpillars, predation by ectothermic arthropods was higher close to the equator (where temperatures are consistently warmer), but attacks by endothermic birds and mammals showed no relationship with latitude (Roslin et al. 2017). This suggests that habitat and latitude may have important and inter- acting effects on relationships between conspicuousness/ color and predation risk.

Here, we use an experimental approach to determine whether and how predation pressure is related to vegetative cover, latitude, sex, and conspicuousness using 3-D-printed model fairy-wrens, a genus of songbirds (Malurus) with pronounced interspecific variation in the conspicuousness of female plumage. Model fairy-wrens were painted to mimic conspicuously colored males, conspicuously colored females, and dull females and placed in eight habitats across Australia. We tested whether the strength and direction of the relationships between predation, latitude, and vegetation structure differed for conspicuous versus dull individuals or males versus females. We predicted that predation rates would be higher in open habitats (due to increased visibility), higher when models contrast more with environmental backgrounds (due to increased detectability), and higher when further from the equator (Johnson et al. 2013; Karubian 2013; Dale et al. 2015; Price 2015; Simpson et al. 2015; Medina et al. 2017). We also predicted that the conspicuous male and female models would suffer disproportionately higher attack rates than the cryptic, dull female model, particularly in open habitat. Because the models were stationary and provided only visual cues, we could isolate color from other factors that influence predation risk such as behavior.

\section{Material and Methods Study System}

The Malurids (fairy-wrens, emu-wrens, and grasswrens) are an excellent group for investigating the eco-evolutionary forces that shape female coloration. Male nuptial plumage is conspicuous in all species of fairy-wrens and emu-wrens (though not in grasswrens). In contrast, female color varies widely across species (from drab brown to strikingly blue and white; fig. 1) and appears to be responding to current or recent selective pressures (Johnson et al. 2013; Karubian 2013). Yet despite these marked differences in plumage and habitat, this clade remains consistent in breeding biology. In all species, the female alone constructs a domed nest and incubates and broods the young; the male and subordinates assist only in provisioning and nest defense (Rowley and Russell 1997).

Previous work has shown that female plumage is more conspicuous in species that reside closer to the equator (Karubian et al. 2011; Johnson et al. 2013; Karubian 2013). However, Malurids live in habitats that span desert scrubland to tropical rain forest (fig. 1; Karubian 2013), and many environmental variables change with latitude (rainfall, vegetation, predator guilds, etc.). A separate study identified a specific environmental variable - vegetative coverthat appears to be related to female, but not male, plumage 
(a)



Malurus a. assimilis

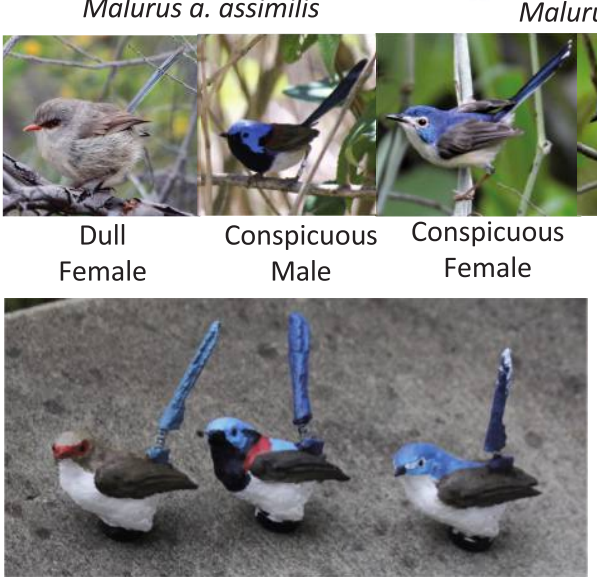

(b) Site

\begin{tabular}{|c|c|c|c|}
\hline $\begin{array}{l}\text { Site } \\
\text { code }\end{array}$ & Site (clockwise on map) & $\begin{array}{l}\text { Veg } \\
\text { score }\end{array}$ & Lat \\
\hline MS & $\begin{array}{c}\text { AWC's Mornington Wildlife Sanctuary } \\
\text { riparian forest in monsoonal } \\
\text { grassland }\end{array}$ & -1.7 & -17.5 \\
\hline KD & $\begin{array}{c}\text { Kakadu National Park } \\
\text { sandstone outcrops in monsoonal } \\
\text { grassland }\end{array}$ & 0.2 & -13.4 \\
\hline $\mathrm{CN}$ & $\begin{array}{l}\text { Cairns area } \\
\text { tropical rainforest }\end{array}$ & 1.0 & -16.9 \\
\hline LS & $\begin{array}{l}\text { Lake Samsonvale area } \\
\text { temperate mixed forest/grassland }\end{array}$ & 3.3 & -27.3 \\
\hline $\mathrm{CP}$ & $\begin{array}{c}\text { Campbell Park } \\
\text { dry, open eucalypt forest }\end{array}$ & -0.7 & -35.3 \\
\hline SP & $\begin{array}{c}\text { Serendip Sanctuary } \\
\text { dry, open eucalypt forest }\end{array}$ & -0.2 & -37.8 \\
\hline BF & $\begin{array}{l}\text { Brookfield Conservation Park } \\
\text { mallee scrub }\end{array}$ & -1.9 & -34.4 \\
\hline SB & $\begin{array}{l}\text { Smithbrook Nature Reserve } \\
\text { temperate eucalypt rainforest }\end{array}$ & -0.1 & -34.4 \\
\hline
\end{tabular}

Figure 1: $a$, Map of Australia, with stars marking the location of the field sites. $b$, Table with field sites, vegetation scores, and latitude; site code corresponds to the map in $a$. c , Photographs of the representative species with the hand-painted 3-D models below: from left, female and male purple-backed fairy-wrens (Malurus assimilis assimilis) and female and male lovely fairy-wrens (Malurus amabilis); male lovely fairywren shown only to illustrate similarity to male purple-backed fairy-wren. Photo credits, clockwise from left: Kaspar Delhey, Kristal E. Cain, Patrick De Geest, Patrick De Geest, and Kristal E. Cain.

conspicuousness in this family (Medina et al. 2017). Avian predators are the most common cause of (extrinsic) mortality for foraging adult fairy-wrens (Rowley and Russell 1997; McQueen et al. 2017), and most avian predators rely on visual cues while hunting. Taken together, this suggests that predation may make conspicuous coloration more costly, particularly in open habitats and at high latitudes, and thus the previously observed latitudinal patterns in female coloration are driven by differences in vegetation altering the levels of predation pressure.

\section{Model Design and Construction}

We created three different types of model fairy-wren: conspicuous male, dull female, and conspicuous female, representing a male and female purple-backed fairy-wren (subspecies Malurus assimilis assimilis) and a female lovely fairy-wren (Malurus amabilis), respectively (fig. 1c). The Malurus genus includes 10 Australian species, with three subgroups (Driskell et al. 2011; Joseph et al. 2013; Marki et al. 2017;
McLean et al. 2017). Female plumage shows the greatest variation in the chestnut-shouldered subgroup, ranging from the dull brown of female purple-backed fairy-wrens (M. $a$. assimilis) to the conspicuous blue/white female of the lovely fairy-wren (M. amabilis; fig. 1). The exact nature of the relationship between purple-backed and lovely fairy-wrens is still unresolved, but they are likely to be sister species (McLean et al. 2012, 2017; Joseph et al. 2013). Male purple-backed and lovely fairy-wrens have very similar patterns and colors, though male lovely fairy-wrens are slightly darker blue (fig. 1).

To build the models, we first created a 3-D model of a fairy-wren by scanning at the University of Melbourne Digitisation Centre a taxidermic mount of a female superb fairywren (Malurus cyaneus) on loan from the Melbourne $\mathrm{Mu}-$ seum. This species is similar in size and shape to the species used for the experiment (Rowley and Russell 1997). We used 3-D printers at the University of Melbourne School of Engineering to produce 60 exact replicates in acrylonitrile butadiene styrene plastic (see appendix, available online) and painted them with Resene (Lower Hutt, New Zealand) 
paint. For the white plumage on the belly of all three models and the eye mask of the conspicuous female (fig. 1), which reflect in ultraviolet (UV) light, we used UV reflective paints designed for duck decoys (Reel Wing Decoys, Fargo, ND). To increase the realism of the model, the tails were detached at the base and reattached with a spring. This permitted small tail movements in response to slight breezes, mimicking fairy-wren movements while foraging. On the ventral surface of each model, we glued a strong magnet, which allowed us to attach the model to a metal stake. This prevented the models from being dislodged by wind, while also allowing for noticeable disturbance by animals. We used preliminary trials to confirm that magnet strength was sufficient in strong wind and to optimize camera positioning; models were never dislodged by wind. Each exemplar (individual model) was labeled with a unique identifier on the bottom of the magnet. Visual modeling (Vorobyev and Osorio 1998) indicated that the hand-painted models were very similar in color to their natural counterparts (contrast was less than 1.5 just noticeable differences [JND] for all three models) and have similar contrast to natural backgrounds (less than 2.5 JND); see "Model Matching and Contrast with Natural Counterparts" in the appendix.

\section{Field Sites and Vegetation Cover}

We selected eight field sites (fig. 1) occupied by fairy-wrens with habitat structure varying from very closed to very open. To objectively assess vegetative cover, we downloaded from the Wisconsin Center for Sustainability and the Global Environment (nelson.wisc.edu) three raster files with information on potential vegetation, evapotranspiration, and net primary productivity (NPP); we also downloaded the leaf area index (LAI) and enhanced vegetation index (EVI) from the Atlas of Living Australia (www.ala.org.au). We extracted these values for each starting coordinate of all transects using the free software QGIS. Because the data in the five raster files were highly correlated, we used these measures to generate a principal component using the covariance matrices. The first principal component (PC1) obtained from this analysis represented $55 \%$ of the variation (eigenvalue: 2.8 ; loadingspotential vegetation: -0.364 ; evapotranspiration: 0.3767 ; NPP mean: 0.5315; LAI: 0.4781; EVI: 0.4627). High PC1 values (vegetation score) represent areas with high vegetation density (e.g., dense forests), whereas low values represent open areas (e.g., grasslands and savannahs).

\section{Predation Experiments}

At each site, we set up 4-7 separate transects of 60 models (20 each of the three model types; see above). Models were placed approximately $5 \mathrm{~m}$ apart on bare ground or in short vegetation that did not obscure the model to simulate for- aging birds (all fairy-wren species are frequently found foraging on or near the ground; Tidemann 2016). Fairy-wrens are cooperative breeders and are commonly observed foraging in small groups, so such densities are well within normal observations. Models were placed in alternating order (conspicuous male, conspicuous female, dull female $\times 20$ ). We recorded the unique identifier for each model as it was placed. All models were set out between 11 a.m. and 3 p.m. and remained in place for $48 \mathrm{~h}$. Transects were run one at a time; that is, all 60 models were placed on a single transect, left in place for $48 \mathrm{~h}$, and then set into a new transect. In the event of heavy wind or rain, we waited an extra $24-48 \mathrm{~h}$ or until the weather subsided before starting a new transect. The orientation of each transect depended on field site topography, and transects were arranged at least $200 \mathrm{~m}$ apart. Every $24 \mathrm{~h}$, all models were checked for signs of attack by a predator (hit; e.g., knocked off stake or knocked sideways but still held onto stake by the magnet). Models hit in the first $24 \mathrm{~h}$ were repositioned. We set transects six times at the Lake Samsonvale site, seven times at the Mornington site, four times at the Serendip site, and five times for the remaining five field sites, for a total of 2,511 unique model placements ( $\sim 5$ transects of 60 models, eight field sites). To confirm that models that were knocked off their perches (hit) were actual attacks and to identify the predators, we monitored 2-6 models in every transect using two Bushnell Aggressor (Kansas City, MO) camera traps placed near the mounts. All camera footage was then inspected visually to determine which animals interacted with the models and whether the animals attacked the model, failed to contact the model, or dislodged it accidently without attacking (see table A4 and "Camera-Monitored Models" in the appendix; tables A1-A5 are available online).

\section{Site-Specific Model Contrast against Backgrounds}

One component of detectability or conspicuousness is the amount of chromatic and achromatic contrast that an animal shows relative to its background habitat (Endler 1978; Delhey et al. 2013). To determine whether the degree of contrast varied across field sites and whether contrast was related to the frequency of attack, we compared the reflectance spectra of each model with backgrounds at each study site (excluding Serendip). Because all replicates of each model type were painted with the same paints at the same time, model spectra were taken from a single model exemplar. To quantify background spectra, we randomly selected five model locations at each study site. At each location, measurements of background colors were taken around the model on the ground it was placed on (e.g., sand, rock, grass). Spectra were measured with a Jaz spectrometer (Ocean Optics, Largo, FL) 10-15 times at each model location (50-75 spectra per field site). Spectra were collected in the same standardized man- 
ner and with the same equipment used to measure the model spectra. We also measured latency of human observers to locate the models on seven transects at three field sites (for further detail, see "Model Conspicuousness to Human Observers" in the appendix). While human vision is more limited than avian vision, recent work suggests that, within the visual spectrum, human vision is capable of discerning most of the meaningful variation in bird plumage (Bergeron and Fuller 2018).

\section{Analysis}

We used visual modeling to calculate the chromatic and achromatic contrasts, as perceived by the avian visual system, between the color of the models and their natural counterparts, and between models and the site-specific background spectra (following Delhey et al. 2013; R code as in Delhey et al. 2015). These contrasts, or visual distances, were averaged according to the proportion of the model that was covered in that plumage patch to produce a weighted composite contrast value (more detail in "Model Matching and Contrast with Natural Counterparts" in the appendix). Because we were interested in how contrast related to avian predation pressure, we used violet-sensitive (V-type) visual sensitivities (Endler and Mielke 2005), which correspond to most avian predators (e.g., falcons, hawks, kingfishers; Ödeen and Håstad 2013). However, we repeated all calculations using ultravioletsensitive (U-type) visual sensitivities to assess the effect of variation in this parameter on our conclusions. All computations were completed in R, version 3.4.0 (R Core Team 2017).

To determine which factors influenced predation risk and how those relationships differed among 3-D models, we used generalized linear mixed models (GLMM) with a binomial error distribution (lme4 package). The response variable was whether the 3-D model was hit (yes/no), explanatory variables included model type (conspicuous male, conspicuous female, dull female), and landscape and site-specific measures. However, because model contrast measures were correlated with vegetation scores and latitude (table A5), we used two separate analyses to avoid problems of collinearity (Freckleton et al. 2016). In the first analysis, we examined how landscape-level factors influenced predation rates and whether those effects differed according to model type. To do so, we examined the effect of vegetation PC and latitude (both standardized), as well as interactions between model type and the other two variables. In the second model, we examined whether model contrasts (using V-type sensitivities) with the site-specific backgrounds influenced predation rates and whether those effects differed according to model type (see appendix for analysis using U-type sensitivities). To do so, we examined the effect of chromatic contrast and achromatic contrast (both standardized) and interactions between model type and both chromatic and achromatic contrasts.
For both analyses, we also included site (large-scale location; fig. 1) and model ID as random effects to account for nonindependence of the data. Because one site had a high number of false hits (Campbell Park; see below), we repeated these analyses excluding that site; both versions of the models are presented. All analyses were run in R, version 3.4.0 (R Core Team 2017; package lme4: Bates et al. 2014). Data for analyses are deposited in the Dryad Digital Repository: https://doi.org /10.5061/dryad.t63qq52 (Cain et al. 2019).

\section{Results}

Overall, 331 of the 2,511 unique model placements (13.2\%) were hit (dislodged). There was no overall difference in the number of each model type attacked (percentage hit by model type: conspicuous male $12.9 \%$; conspicuous female $13.1 \%$; dull female $13.6 \%$ ). However, hit rates varied dramatically between sites (4\% at Lake Samsonvale to $47 \%$ at Campbell Park). Of the camera-monitored models (table A4; $N=81$ ), we recorded 13 hits: nine instances where the model was attacked and four instances where the model was dislodged with no evidence of attack, that is, false hits (e.g., knocked over while foraging). All occurrences of false attacks were at Campbell Park, where there were seven total hits captured by photograph: three actual attacks and four false hits. Cases of false hits involved the model being dislodged by a foraging eastern grey kangaroo (Macropus giganteus) or European rabbit (Oryctolagus cuniculus). Across all sites, animals recorded attacking the models were predominantly birds (three times by an Australian magpie Cracticus tibicen; once by a currawong Strepera graculina, both avian predators; and three times by a white-winged chough Corcorax melanorhamphos, an avian ground-foraging generalist; fig. A6; figs. A1-A7 are available online), but in two instances, we observed mammals biting the model (red fox Vulpes vulpes, swamp wallaby Wallabia bicolor). During preliminary tests, we recorded two additional attacks (both times by laughing kookaburra Dacelo novaeguineae, an avian predator; fig. A6).

\section{Associations between Latitude, Vegetation, and Predation Risk}

At the landscape level, attack rates were lower when closer to the equator for all model types (table 1). Attack rates were also lower in more closed habitats (higher vegetation scores). This effect varied according to model type (table $1 a$ ) but in the opposite direction to our predictions. Attack rates increased in open habitat more for the dull and conspicuous female models than for the conspicuous male (fig. 2). Conversely, the probability of attack was reduced in closed habitat for all models but at a higher rate for the female models than the male model (fig. 2a). Excluding the site with detected false hits (table $1 b$; Campbell Park) or examining only the 
Table 1: Summary of generalized linear mixed models (binomial, logit error link) testing for effects of latitude, vegetation, and model type on the probability of a model being hit

\begin{tabular}{|c|c|c|c|}
\hline Fixed effects & Estimate $\pm \mathrm{SE}$ & $z$ values $/ \chi^{2}$ & $P$ value \\
\hline \multicolumn{4}{|l|}{$\begin{array}{l}\text { a. Hit }(\mathrm{y} / \mathrm{n}), N=2,511, \chi^{2}=26, P=.001 \\
\text { including all data }\end{array}$} \\
\hline Intercept & $-2.3 \pm .2$ & & \\
\hline Model type & & .08 & .9 \\
\hline Conspicuous female ${ }^{a}$ & $-.06 \pm .2$ & -.3 & .8 \\
\hline Conspicuous male ${ }^{a}$ & $.2 \pm .2$ & .8 & .4 \\
\hline Vegetation score & $-.7 \pm .2$ & -2.9 & .004 \\
\hline Latitude & $-.7 \pm .2$ & -3.2 & .002 \\
\hline Model type $\times$ vegetation score & & 8.2 & .02 \\
\hline Conspicuous female $\times$ vegetation score ${ }^{\mathrm{a}}$ & $-.1 \pm .2$ & -.6 & .58 \\
\hline Conspicuous male $\times$ vegetation score ${ }^{a}$ & $.4 \pm .2$ & 2.1 & .036 \\
\hline Model type $\times$ latitude & & 1.3 & .5 \\
\hline Conspicuous female $\times$ latitude ${ }^{a}$ & $.05 \pm .2$ & .3 & .8 \\
\hline \multirow[t]{2}{*}{ Conspicuous male $\times$ latitude ${ }^{a}$} & $.2 \pm .2$ & 1.1 & .3 \\
\hline & Variance $\pm \mathrm{SD}$ & & \\
\hline \multicolumn{4}{|l|}{ Random effects: } \\
\hline Unique model ID & $.004 \pm .07$ & & \\
\hline Study site & $.3 \pm .5$ & & \\
\hline \multicolumn{4}{|l|}{$\begin{array}{l}\text { b. Hit }(\mathrm{y} / \mathrm{n}), N=2,214, \chi^{2}=86.5, P<.0001 \text {, } \\
\quad \text { excluding Campbell Park }\end{array}$} \\
\hline Intercept & $-2.5 \pm .2$ & & \\
\hline Model type & & .3 & .9 \\
\hline Conspicuous female ${ }^{a}$ & $-.1 \pm .2$ & -.5 & .63 \\
\hline Conspicuous male ${ }^{\mathrm{a}}$ & $.16 \pm .2$ & .8 & .4 \\
\hline Vegetation score & $-.57 \pm .18$ & -3.1 & .002 \\
\hline Latitude & $-.60 \pm .16$ & -3.8 & .0002 \\
\hline Model type $\times$ vegetation score & & 8.3 & .02 \\
\hline Conspicuous female $\times$ vegetation ${ }^{a}$ & $-.13 \pm .24$ & -.6 & .6 \\
\hline Conspicuous male $\times$ vegetation ${ }^{\mathrm{a}}$ & $.44 \pm .21$ & 2.1 & .03 \\
\hline Model type $\times$ latitude & & 1.1 & .6 \\
\hline Conspicuous female $\times$ latitude $\mathrm{a}^{\mathrm{a}}$ & $.09 \pm .20$ & .5 & 6 \\
\hline \multirow[t]{2}{*}{ Conspicuous male $\times$ latitude ${ }^{\mathrm{a}}$} & $.20 \pm .19$ & 1.1 & .3 \\
\hline & Variance \pm SD & & \\
\hline \multicolumn{4}{|l|}{ Random effects: } \\
\hline Unique model ID & $.000 \pm .0000$ & & \\
\hline Study site & $.04 \pm .2$ & & \\
\hline
\end{tabular}

Note: Provided are $\chi^{2}$ values for main effects and $z$-values for parameter estimates. Negative estimates indicate a reduction in the probability of attack, relative to the intercept and reference levels of factors. Boldface indicates significant effects.

${ }^{a}$ Relative to dull female.

subset of models that were monitored by cameras (results in "Camera-Monitored Models" in the appendix) did not alter these patterns. Excluding the conspicuous female model (which was novel in five of the eight study sites) also had no overall effect on the observed patterns (results in "Novel Model Type" in the appendix).

\section{Associations between Plumage Contrast and Predation Risk}

The degree to which models contrasted with background habitat color varied according to both latitude and vegeta- tion score. Most notably, chromatic contrast increased as habitats became more closed and at latitudes closer to the equator (see table A5). As expected, dull female models contrasted less than the conspicuous models in all habitats. The average chromatic contrast for the dull female across all habitats $(5.8 \pm 0.2$ JND for V-type eyes, $4.1 \pm 0.2$ JND for U-type eyes) was lower than the contrast for the other two models using both $\mathrm{U}$ and $\mathrm{V}$ vision models (conspicuous female: V $7.4 \pm 0.3 \mathrm{JND}, \mathrm{U} 7.9 \pm 0.3 \mathrm{JND}$; conspicuous male: V 7.9 \pm 0.3 JND, U $8.4 \pm 0.2$ JND; V-type eyes: ANOVA $F_{2,21}=78.9, P<.0001$, U-type eyes: $F_{2,21}=76.9, P<$ 


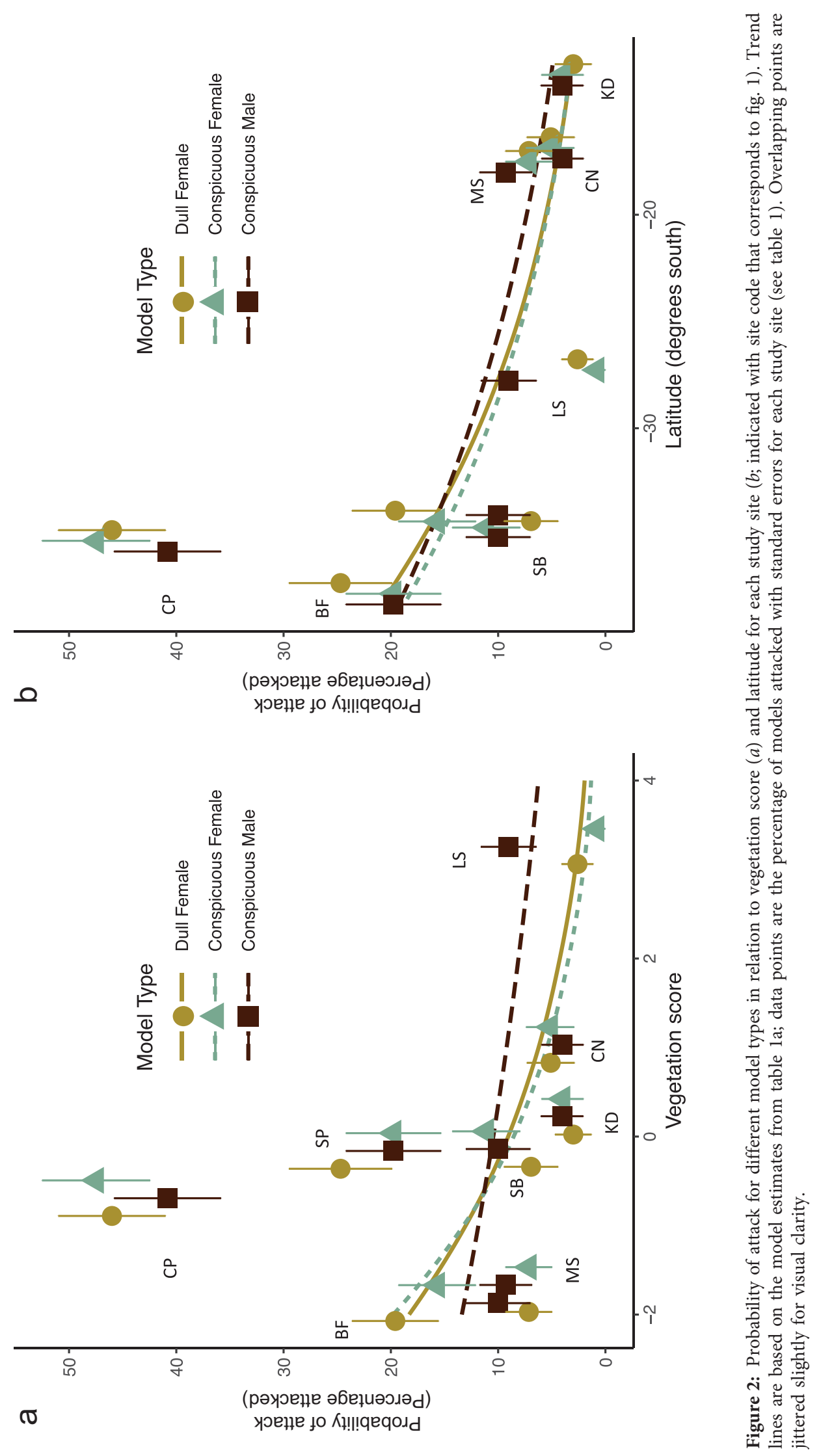

This content downloaded from 145.116.172.156 on January 28, 2019 01:00:04 AM All use subject to University of Chicago Press Terms and Conditions (http://www.journals.uchicago.edu/t-and-c). 
.0001). Achromatic contrast showed similar patterns, though the differences between models were less than 1 JND and thus unlikely to be detectable or biologically relevant (dull female: $3.3 \pm 0.1 \mathrm{JND}$; conspicuous female: $3.8 \pm 0.1 \mathrm{JND}$; conspicuous male: $4.0 \pm 0.1 \mathrm{JND} ; 3.7 \pm 0.3 \mathrm{JND}$; ANOVA $\left.F_{2,21}=10.8, P=.0008\right)$. These model contrast differences were reflected in the latencies of human observers to locate models; human observers in all sites took significantly more time to find the dull female model (fig. A5; table A2).

Contrary to our predictions, the probability of being attacked was negatively but not significantly associated with chromatic contrast and unrelated to achromatic contrast. Neither relationship varied according to model type (fig. 3; table $2 a$, model including all sites except Serendip, where no background measurements were taken). Excluding the site with detected false hits (table $2 b$, Campbell Park), the negative relationship between chromatic contrast and the probability of predation was statistically significant for all model types. Further, there was a significant effect of model type such that the dull female model was attacked more frequently, after controlling for contrast, than the other model types. Achromatic contrast was not a significant predictor in this model; nor were there significant model type interactions with achromatic contrast (table $2 b$ ). Models using U-type sensitivities showed the same patterns with weaker effects (table A3).

\section{Discussion}

We investigated how vegetation, latitude, and plumage conspicuousness influence predation pressure across Australia using 3-D models that mimicked males and females that differed in degree of plumage conspicuousness. We found that for all model types, predation risk was greater at higher latitudes and in more open habitat. Unexpectedly, we found no relationship between overall attack frequency and the conspicuousness of the model (i.e., model type-conspicuous male, conspicuous female, and dull female) or the degree to which the models contrasted with their backgrounds. Further, we predicted that the increased attack rates in open habitats would be more exaggerated in the conspicuous models but instead found that the rate of increase in attack rate was greater for the two female models than for the highly contrasting conspicuous male models. To our knowledge, these data provide the first estimates of predation pressure on adult birds across Australia and reveal important differences in the selective environment birds face in different habitats. However, these findings provide no support for the hypothesis that increased conspicuousness is associated with greater predation pressure.

We are not aware of any other studies that so explicitly examine the relationship between color and predation risk, particularly at such a large scale and while also considering local background color and contrast. However, all studies have limitations, and there are important caveats to consider when interpreting our results. First, it is important to note that we did not quantify predator attention, only attack rates, and predators may not attack the first model they observed. Fairy-wrens are group living, and predators may be selective about which group member they attack. In other words, predators may use conspicuous group members to locate their preferred targets. It is also unlikely that we estimated total predation pressure. Our models provided only visual stimuli and very limited movement. While avian predators rely on visual cues, reptilian (e.g., snakes and monitor lizards) and mammalian predators may rely on other cues that our models did not provide (smell, sound, body heat). Thus, our estimates are more likely to reflect relative risk to avian predators associated with conspicuous coloration across sites rather than total predator risk. Nevertheless, avian predators are the most likely source of mortality for a foraging adult fairy-wren (Rowley and Russell 1997; McQueen et al. 2017), and this pattern was reflected in the camera-recorded attacks. Further, because the models are not moving, our results allow us to disentangle color from behavior as a factor driving predation risk. It is also important to note that our predation pressure estimates are for foraging birds rather than birds on the nest, which likely experience different predator pressures. Future research could use a similar approach to address how color, latitude, and habitat interact to influence predation at the nest. Finally, we monitored only a small proportion of the models with cameras and observed some false hits (moved but not attacked). Though these false hits were only observed in one population and excluding that population had no effect on the overall result, we cannot determine whether this also occurred at other sites or whether false hits diluted or strengthened the actual predation patterns.

\section{Latitude and Predation}

Latitude is strongly associated with the frequency and type of biotic interactions, such as predator/prey interactions, that are driven by changes in the abundance and species composition of different functional groups (McKinnon et al. 2010; Díaz et al. 2013; Roslin et al. 2017). Other large-scale studies have found strong latitudinal patterns in predation, generally increasing closer to the equator. For instance, global arthropod predation pressure increases closer to the equator (Roslin et al. 2017), and raptor abundance decreases at very high latitudes (Díaz et al. 2013). However, most studies examining latitude relationships with predation pressure in birds have focused on latitudinal patterns in nest predation rather than adults (e.g., McKinnon et al. 2010; Martin 2015) or inferred predation pressure from raptor densities (Díaz et al. 2013). 




This content downloaded from 145.116.172.156 on January 28, 2019 01:00:04 AM All use subject to University of Chicago Press Terms and Conditions (http://www.journals.uchicago.edu/t-and-c). 
Table 2: Summary of generalized linear mixed models (binomial, logit error link) testing for site-specific effects of chromatic contrast using V-type visual sensitivities, achromatic contrast, and model type

\begin{tabular}{|c|c|c|c|}
\hline Fixed effects & Estimate \pm SE & $z$ values $/ \chi^{2}$ & $P$ value \\
\hline \multicolumn{4}{|c|}{$\begin{array}{l}\text { a. Hit }(\mathrm{y} / \mathrm{n}), N=2,268, \chi^{2}=260, P<.0001 \\
\text { no data for Serendip }\end{array}$} \\
\hline Intercept & $-5.4 \pm 1.7$ & & \\
\hline Model type & & 1.4 & .5 \\
\hline Conspicuous female ${ }^{a}$ & $3.6 \pm 2.1$ & 1.7 & .08 \\
\hline Conspicuous male ${ }^{a}$ & $3.4 \pm 2.3$ & 1.4 & .15 \\
\hline Chromatic contrast & $-2.1 \pm 1.1$ & -1.8 & .07 \\
\hline Achromatic contrast & $-.1 \pm .2$ & -.7 & .5 \\
\hline Model type $\times$ chromatic & & 3.0 & .2 \\
\hline Conspicuous female $\times$ chromatic $^{a}$ & $1.3 \pm 1.0$ & 1.4 & .2 \\
\hline Conspicuous male $\times$ chromatic $^{\mathrm{a}}$ & $1.7 \pm 1.0$ & 1.6 & .1 \\
\hline Model type $\times$ achromatic & $-.5 \pm .8$ & .9 & 6 \\
\hline Conspicuous female $\times$ achromatic $^{\mathrm{a}}$ & $.2 \pm .8$ & -.6 & 6 \\
\hline \multirow[t]{2}{*}{ Conspicuous male $\times$ achromatic ${ }^{a}$} & & .3 & .8 \\
\hline & Variance \pm SD & & \\
\hline \multicolumn{4}{|l|}{ Random effects: } \\
\hline Unique model ID & $.0 \pm .0$ & & \\
\hline Site & $.8 \pm .9$ & & \\
\hline \multicolumn{4}{|c|}{$\begin{array}{r}\text { b. Hit }(\mathrm{y} / \mathrm{n}), N=1,971, \chi^{2}=38, P<.0001, \\
\text { excludes Serendip and Campbell Park }\end{array}$} \\
\hline Intercept & $-6.1 \pm 1.0$ & & \\
\hline Model type & & 11.8 & .003 \\
\hline Conspicuous female ${ }^{a}$ & $3.9 \pm 1.0$ & 3.8 & .0002 \\
\hline Conspicuous male ${ }^{a}$ & $4.0 \pm 1.1$ & 3.7 & .0002 \\
\hline Chromatic contrast $\mathrm{V}$ & $-2.3 \pm .6$ & -3.8 & .0001 \\
\hline Achromatic contrast & $-.2 \pm .2$ & -1.3 & .2 \\
\hline Model type $\times$ chromatic & & 4.9 & .09 \\
\hline Conspicuous female $\times$ chromatic $^{a}$ & $1.9 \pm .9$ & 2.1 & .04 \\
\hline Conspicuous male $\times$ chromatic $^{\mathrm{a}}$ & $1.6 \pm 1.0$ & 1.6 & .11 \\
\hline Model type $\times$ achromatic & & 2.7 & .3 \\
\hline Conspicuous female $\times$ achromatic $^{\mathrm{a}}$ & $-.8 \pm .6$ & -1.3 & .2 \\
\hline \multirow[t]{2}{*}{ Conspicuous male $\times$ achromatic ${ }^{a}$} & $.5 \pm .6$ & .8 & .4 \\
\hline & Variance $\pm S D$ & & \\
\hline \multicolumn{4}{|l|}{ Random effects: } \\
\hline Unique model ID & $.00 \pm .0$ & & \\
\hline Site & $.04 \pm .2$ & & \\
\hline
\end{tabular}

Note: Provided are $\chi^{2}$ values for main effects and $z$-values for parameters estimates. Negative estimates indicate a reduction in the probability of attack, relative to the intercept and reference levels of factors. Boldface indicates significant effects.

${ }^{\text {a }}$ Relative to dull female.

Counter to most latitudinal studies, we found that predation pressure increased with distance from the equator. Previous comparative studies in the Maluridae family (fairy-wrens, emu-wrens, and grasswrens) have found that female coloration is most conspicuous close to the equator (Johnson et al. 2013; Karubian 2013). Our results suggest that weaker predation pressure close to the equator may be a contributing factor in this pattern. It also suggests that predator abundance or density might increase with latitude, but further study is needed to resolve the mechanism underlying this pattern.

\section{Vegetative Structure}

Previous studies examining the role of vegetation in predation pressure have produced mixed results. In North America, predation rates in savannah sparrows (Passerculus sand- 
wichensis) and song sparrows (Melospiza melodia) were higher in mowed pasture than in unmowed pasture (Watts 1990). In contrast, a review examining the effects of agricultural practices on foraging efficiency and predation risk found that for 15 of 20 species, open habitat (shorter vegetation) enhanced foraging efficiency and reduced predation risk, possibly because of improved predator detection (Whittingham and Evans 2004).

Our measure of vegetative cover - a composite of density, primary production, and structure-was strongly associated with predation pressure, over and above latitudinal variation. Our data suggest that adult birds living in open Australian habitats experience higher predation pressure than those in closed habitat, though it is unclear whether this pattern is due to differences in detectability, predator density, or both. Either way, predation pressure is likely to be a stronger selective force for birds in open habitat than birds in closed habitat, which may favor more cryptic plumage, flocking, or vigilance in open habitat. Finally, higher predation in open habitats may have been exacerbated by our model design. Models had a small spring at the base of the tail to allow movement and improve similarity to real birds. When deployed in open habitat, models may have experienced higher wind speeds, resulting in greater tail movement, and attracting more predator attention. Unfortunately, we cannot rule out this possibility. However, this explanation would not explain the observed difference between model types in how attack frequency changed according to habitat structure (discussed below).

\section{Model Contrasts with Background Environments}

To our knowledge, no previous study has tested for a direct relationship between predation risk and conspicuousness relative to site-specific backgrounds in birds. However, similar studies in reptiles and invertebrates have reported that higher contrast increases predation risk. For example, brightly colored males are more conspicuous relative to their backgrounds and suffer higher predation risk in Australian rock dragons (Ctenophorus sp.; Stuart-Fox et al. 2003), and Australian fiddler crabs (Uca vomeris) will reduce contrasting color patches within days of being moved into a simulated highpredation area (Hemmi et al. 2006). Further, studies in birds have also found a positive relationship between plumage conspicuousness and predation, though without considering backgrounds. For instance, the feathers of prey species found in sparrow hawk (Accipiter nisus) nests suggests that brighter plumage (as defined by human observers) increases predation risk in Finland (Huhta et al. 2003), and hawks in Panama were more likely to attack the contrasting, white, immature herons (Egretta caerulea) than the darker, blue adults (Caldwell 1986), though predators may also simply prefer more naïve targets. More recently, an experiment that compared raptor attack rates of conspicuous and cryptic models of the same species found that for four of the six species tested, the conspicuous models were attacked at higher rates (no differences for the other two species; Ruiz-Rodríguez et al. 2013), though here the cryptic models were novel, which may deter predators (Götmark 1994). Together, these data suggest that conspicuous plumage can increase detectability and predation pressure and thus be an important cost driving plumage color variation.

We found that model contrasts varied with the site-specific backgrounds, but we found no support for the hypothesis that increasing contrast increases predation pressure, as the two were not associated. In fact, when the site with observed false attacks was excluded, we found that within model type, increasing contrasts led to a small decrease in attack rates in all three models. Further, there was low variation in achromatic contrast (range 3-4 JNDs) and strong relationships between contrasts and both vegetation cover and latitude. This suggests that the observed relationships between contrast and predation may have been due to the relationships between contrast, vegetation, and latitude. We suggest strong caution is warranted when interpreting these results.

\section{Lack of Model Differences in Predation Pressure}

Because conspicuousness can increase predator detection (see above), we predicted that the model differences in color and contrast across study sites would drive differences in attack rates; that is, that the more conspicuous models (conspicuous male and female) would suffer higher predation pressure than the dull female model, particularly in open habitat, where visibility is improved. As predicted, human observers detected conspicuous models faster than the dull female model. However, we found no overall differences in attack rates according to model type. Further, we found that though there was an increase in attack rates in open habitat for all the models, the rate of increase was greater for the two female models than the conspicuous male models. Thus, although coloration and contrast likely play a role in predation pressure, the relationship is not as straightforward as is usually assumedmore conspicuous plumage did not lead to greater predation pressure.

Our results, though unexpected, join a substantial body of empirical evidence suggesting that predators often actively avoid males or conspicuous species or that predators preferentially attack females or cryptic species (Baker and Parker 1979; Götmark 1992, 1994; Götmark et al. 1997; Ruiz-Rodríguez et al. 2013). The unprofitable prey hypothesis argues that conspicuous birds advertise their unprofitability to predators and should consequently suffer less predation pressure than more cryptic birds (Baker and Parker 1979; Götmark and Unger 1994). Alternatively, targeting female-plumaged individuals may be an efficient strategy 
for predators because (1) juvenile birds often have femalelike plumage and are less wary than adults (Nielsen and Drachmann 1999; Kullberg and Lind 2002); (2) females have considerably higher caloric requirements in the breeding season and may be less cautious or vigilant while foraging (Powolny et al. 2014); and (3) dull plumaged birds may be generally less vigilant than conspicuous birds, regardless of caloric needs. In support of this last possibility, a recent study in superb fairy-wrens (Malurus cyaneus) found that in the nonbreeding season, males in conspicuous blue and black nuptial plumage were more vigilant and risk averse than dull brown birds (both females and males in dull plumage; McQueen et al. 2017). Similar results emerge from comparative studies, which found no relationship between interspecies differences in plumage conspicuousness and male mortality in passerines and that females generally have higher mortality rates than males in passerines and waterfowl (Promislow et al. 1992, 1994), though here mortality includes adult predation, the costs of reproductive investment, and predation at the nest (females are more likely to be on the nest). Further research is needed to determine which mechanisms (male avoidance, female preference) are functioning in fairy-wren predators. However, regardless of the mechanism, the resulting pattern is the same-conspicuous colors were not associated with an increase in predation pressure.

\section{Conclusion}

It is a common and long-standing hypothesis that conspicuous plumage is costly due to increased vulnerability to predators and that this is a driving force in female plumage evolution (Wallace 1891). Our results support this hypothesis to some extent; predation pressure was higher in more open habitats and at higher latitudes (where females tend to be dull plumaged) and is likely to play a role in female coloration. However, conspicuous models were not attacked more frequently than cryptic models, and the increased predation pressure in open habitats occurred more dramatically for female models, both dull and conspicuous. These findings suggest a subtle but important caveat to this paradigm. Rather than selection against conspicuous colors per se, it may be that it is the interplay of predator behavior, sex differences in behavior (e.g., vigilance), and conspicuousness against particular environmental backgrounds that is costly for females rather than conspicuous colors alone. This finding adds to others suggesting that differences in costs, relative to benefits, are often an important and understudied factor underlying species differences in the expression of conspicuous traits in females (Promislow et al. 1992; Cain and Rosvall 2014).

\section{Acknowledgments}

The authors would like to acknowledge the students, volunteers, field assistants, and technicians that assisted at each field site and staff at the Australian Wildlife Conservancy's Mornington Wildlife Sanctuary for continued support. Extra thanks to S. Hoobler, N. Svedin, J. Heathcote, and $\mathrm{K}$. Wetten for their assistance in data collection and to $\mathrm{O}$. Branquinho for assistance in model painting and construction. Thanks to the University of Melbourne Digitisation Centre for 3-D scanning and the Department of Engineering Workshop for access to 3-D printers. K.E.C., M.L.H., A.V.L., and R.A.M. were supported by Australian Research Council (ARC) grant DP150101652 to R.A.M., N.E.L., and K.D.; I.M. and N.E.L. were supported by ARC grant DP110101966 to N.E.L.; L.B. and K.D. were supported by ARC Discovery Early Career Researcher Award fellowships (DE130100174 to L.B., DE120102323 to K.D.); and A.P. was supported by an ARC Future Fellowship (FT 110100505). Research was conducted under the following permits: animal ethics 1212668.2 and scientific research WISP13237913 and RK865 to R.A.M., M.L.H., and K.E.C. Research was approved by the Australian Bird and Bat Banding Scheme (ABBBS license 2230 to A.P.), the Western Australian Department of Environment and Conservation, the Australian Wildlife Conservancy, and the ethics committees of the School of Biological Sciences at Monash University (BSCI/ 2011/28, BSCI/2015/11). The authors would also like to acknowledge the insight and contributions of the reviewers and editors, whose efforts greatly improved the quality of this publication.

\section{Literature Cited}

Amundsen, T. T. 2000a. Female ornaments: genetically correlated or sexually selected. Pages 133-154 in Y. Espmark, T. Amundsen, and G. Rosenqvist, eds. Animal signals: signalling and signal design in animal communication. Tapir Academic, Trondheim.

. $2000 b$. Why are female birds ornamented? Trends in Ecology and Evolution 15:149-155.

Andersson, M. 1994. Sexual selection. Princeton University Press, Princeton, NJ.

Baker, R. R., and G. A. Parker. 1979. The evolution of bird coloration. Philosophical Transactions of the Roval Society B 287:63130.

Bates, D., M. Maechler, B. Bolker, and S. Walker. 2014. lme4: linear mixed-effects models using Eigen and S4. R Package, version 1.1-7. http://CRAN.R-project.org/package $=$ lme 4 .

Bergeron, Z. T., and R. Fuller. 2018. Using human vision to detect variation in avian coloration: how bad is it? American Naturalist 191:269276.

Burns, K. J. 1998. A phylogenetic perspective on the evolution of sexual dichromatism in tanagers (Thraupidae): the role of female versus male plumage. Evolution 52:1219-1224.

Cain, K. E., M. L. Hall, I. Medina, A. V. Leitao, K. Delhey, L. Brouwer, A. Peters, et al. 2019. Data from: Conspicuous plumage does not in- 
crease predation risk: a continent-wide test using model songbirds. American Naturalist, Dryad Digital Repository, https://doi.org/10 .5061/dryad.t63qq52.

Cain, K. E., and K. A. Rosvall. 2014. Next steps for understanding the selective relevance of female-female competition. Frontiers in Ecology and Evolution 2:1-3.

Caldwell, G. S. 1986. Predation as a selective force on foraging herons - effects of plumage color and flocking. Auk 103:494505.

Dale, J., C. J. Dey, K. Delhey, B. Kempenaers, and M. Valcu. 2015. The effects of life history and sexual selection on male and female plumage colouration. Nature 527:367-370.

Darwin, C. 1872. The descent of man, and selection in relation to sex. J. Murray, London.

Delhey, K., V. Delhey, B. Kempenaers, and A. Peters. 2015. A practical framework to analyze variation in animal colors using visual models. Behavioral Ecology 26:367-375.

Delhey, K., M. L. Hall, S. A. Kingma, and A. Peters. 2013. Increased conspicuousness can explain the match between visual sensitivities and blue plumage colours in fairy-wrens. Proceedings of the Roval Society B 280:20121771.

Díaz, M., A. P. Møller, E. Flensted-Jensen, T. Grim, J. D. IbáñezÁlamo, J. Jokimäki, G. Markó, and P. Tryjanowski. 2013. The geography of fear: a latitudinal gradient in anti-predator escape distances of birds across Europe. PLoS ONE 8:e64634.

Driskell, A. C., J. A. Norman, S. Pruett-Jones, E. Mangall, S. Sonsthagen, and L. Christidis. 2011. A multigene phylogeny examining evolutionary and ecological relationships in the Australo-papuan wrens of the subfamily Malurinae (Aves). Molecular Phvlogenetics and Evolution 60:480-485.

Dunn, P. O., J. K. Armenta, and L. A. Whittingham. 2015. Natural and sexual selection act on different axes of variation in avian plumage color. Science Advances 1:e1400155.

Endler, J. A. 1978. A predator's view of animal color patterns. Pages 319-364 in M. K. Hecht, W. C. Steere, and B. Wallace, eds. Evolutionary biology. Vol. 11. Plenum, New York.

Freckleton, R. P., B. J. Hatchwell, and J. P. Green. 2016. Variation in helper effort among cooperatively breeding bird species is consistent with Hamilton's rule. Nature Communications 7:1-7.

Godin, J. G. J., and H. E. McDonough. 2003. Predator preference for brightly colored males in the guppy: a viability cost for a sexually selected trait. Behavioral Ecology 14:194-200.

Götmark, F. 1992. Anti-predator effect of conspicuous plumage in a male bird. Animal Behaviour 44:51-55.

1994. Does a novel bright colour patch increase or decrease predation? red wings reduce predation risk in European blackbirds. Proceedings of the Roval Society B 256:83-87.

Götmark, F., and A. Hohlfält. 1995. Bright male plumage and predation risk in passerine birds: are males easier to detect than females? Oikos 74:475-484.

Götmark, F., P. Post, J. Olsson, and D. Himmelmann. 1997. Natural selection and sexual dimorphism: sex-biased sparrowhawk predation favours crypsis in female chaffinches. Oikos 80:540.

Götmark, F., and U. Unger. 1994. Are conspicuous birds unprofitable prey? field experiments with hawks and stuffed prey species. Auk 111:251-262.

Hemmi, J. M., J. Marshall, W. Pix, M. Vorobyev, and J. Zeil. 2006. The variable colours of the fiddler crab Uca vomeris and their relation to background and predation. 209:4140-4153.
Huhta, E., S. Rytkönen, and T. Solonen. 2003. Plumage brightness of prey increases predation risk: an among-species comparison. Ecology 84:1793-1799.

Irwin, R. E. 1994. The evolution of plumage dichromatism in the New World blackbirds: social selection on female brightness. American Naturalist 6:890-907.

Johnson, A. E., J. J. Price, and S. Pruett-Jones. 2013. Different modes of evolution in males and females generate dichromatism in fairywrens (Maluridae). Ecology and Evolution 3:3030-3046.

Joseph, L., S. V. Edwards, and A. J. McLean. 2013. The Maluridae: inferring avian biology and evolutionary history from DNA sequences. Emu 113:195-207.

Karubian, J. 2013. Female ornamentation in Malurus fairy-wrens: a hidden evolutionary gem for understanding female perspectives on social and sexual selection. Emu 113:248-258.

Karubian, J., W. R. Lindsay, H. Schwabl, and M. S. Webster. 2011. Bill coloration, a flexible signal in a tropical passerine bird, is regulated by social environment and androgens. Animal Behaviour 81:795-800.

Kullberg, C., and J. Lind. 2002. An experimental study of predator recognition in great tit fledglings. Ethology 108:429-441.

Lande, R. 1980. Sexual dimorphism, sexual selection, and adaptation in polygenic characters. Evolution 34:292-305.

Marki, P. Z., K. A. Jønsson, M. Irestedt, J. M. T. Nguyen, C. Rahbek, and J. Fjeldsa. 2017. Supermatrix phylogeny and biogeography of the Australasian Meliphagides radiation (Aves: Passeriformes). Molecular Phylogenetics and Evolution 107:516-529.

Martin, T. E. 1995. Avian life history evolution in relation to nest sites, nest predation, and food. Ecological Monographs 65:101-127.

-2015. Age-related mortality explains life history strategies of tropical and temperate songbirds. Science 349:966-970.

Matysioková, B., V. Remeš, and A. Cockburn. 2017. Broad-scale variation in sexual dichromatism in songbirds is not explained by sex differences in exposure to predators during incubation. $\underline{\text { Journal of }}$ Avian Biology 48:1322-1330.

McKinnon, L., P. A. Smith, E. Nol, J. L. Martin, F. I. Doyle, K. F. Abraham, H. G. Gilchrist, R. I. G. Morrison, and J. Bêty. 2010. Lower predation risk for migratory birds at high latitudes. Science 327:326-327.

McLean, A. J., L. Joseph, A. Toon, D. J. Schmidt, A. Drew, I. J. Mason, and J. M. Hughes. 2017. Reassessment of a possible case of intraspecific gene flow across Australia's Great Dividing Range in the variegated fairy wren, Malurus lamberti (Aves: Maluridae), and its systematic consequences. Biological Journal of the Linnean Society 122:210-223.

McLean, A. J., A. Toon, D. J. Schmidt, and L. Joseph. 2012. Speciation in chestnut-shouldered fairy-wrens (Malurus spp.) and rapid phenotypic divergence in variegated fairy-wrens (Malurus lamberti): a multilocus approach. Molecular Phylogenetics and Evolution 63:668-678.

McQueen, A., A. C. Naimo, N. Teunissen, R. D. Magrath, K. Delhey, and A. Peters. 2017. Bright birds are cautious: seasonally conspicuous plumage prompts risk avoidance by male superb fairy-wrens. Proceedings of the Roval Societv B 284:20170446.

Medina, I., K. Delhey, A. Peters, K. E. Cain, M. L. Hall, R. A. Mulder and N. E. Langmore. 2017. Habitat structure is linked to the evolution of plumage colour in female, but not male, fairy-wrens. BMC Evolutionary Biology 17:35.

Nielsen, J. T., and J. Drachmann. 1999. Prey selection of Goshawks Accipiter gentilis during the breeding season in Vendsyssel, Denmark. Dansk Orn Foren Tidsskr 93:85-90. 
Ödeen, A., and O. Håstad. 2013. The phylogenetic distribution of ultraviolet sensitivity in birds. BMC Evolutionary Biology 13:36.

Powolny, T., V. Bretagnolle, A. Aguilar, and C. Eraud. 2014. Sexrelated differences in the trade-off between foraging and vigilance in a granivorous forager. PLoS ONE 9:e101598.

Price, J. J. 2015. Rethinking our assumptions about the evolution of bird song and other sexually dimorphic signals. Frontiers in Ecology and Evolution 3:1-6.

Price, T., and G. L. Birch. 1996. Repeated evolution of sexual color dimorphism in passerine birds. Auk 113:842-848.

Promislow, D. E., R. Montgomerie, and T. E. Martin. 1992. Mortality costs of sexual dimorphism in birds. Proceedings of the Roval Societv B 250:143-150.

1994. Sexual selection and survival in North American waterfowl. Evolution 48:2045-2050.

R Core Team. 2017. R: a language and environment for statistical computing. R Foundation for Statistical Computing, Vienna. http:// www.R-project.org/.

Roslin, T., B. Hardwick, V. Novotny, W. K. Petry, N. R. Andrew, A. Asmus, I. C. Barrio, et al. 2017. Higher predation risk for insect prey at low latitudes and elevations. Science 356:742-744.

Rowley, I., and E. M. Russell. 1997. Fairy-wrens and grasswrens. Oxford University Press, Oxford.

Ruiz-Rodríguez, M., J. M. Avilés, J. J. Ceurvo, D. Parejo, F. Ruano, C. Zamora-Muñoz, F. Sergio, L. López-Jiménez, A. Tanferna, and M. Martín-Vivaldi. 2013. Does avian conspicuous colouration increase or reduce predation risk? Oecologia 173:83-93.

Simpson, R. K., M. A. Johnson, and T. G. Murphy. 2015. Migration and the evolution of sexual dichromatism: evolutionary loss of female coloration with migration among wood-warblers. Proceedings of the Roval Societv B 282:20150375.

Stuart-Fox, D. M., A. Moussalli, N. J. Marshall, and I. P. F. Owens. 2003. Conspicuous males suffer higher predation risk: visual modelling and experimental evidence from lizards. Animal Behaviour 66:541-550.

Tidemann, S. C. 2016. Use of space, foraging behaviour and strategies of survival among three coexisting species of fairy-wrens (Malurus). Emu 104:31-36.

Tobias, J. A., R. Montgomerie, and B. E. Lyon. 2012. The evolution of female ornaments and weaponry: social selection, sexual selection and ecological competition. Philosophical Transactions of the Roval Societv B 367:2274-2293.
Vignieri, S. N., J. G. Larson, and H. E. Hoekstra. 2010. The selective advantage of crypsis in mice. Evolution 64:2153-2158.

Vorobyev, M., and D. Osorio. 1998. Receptor noise as a determinant of colour thresholds. Proceedings of the Roval Society B 265:351-358.

Wallace, A. R. 1891. Natural selection and tropical nature. Kessinger, New York.

Watts, B. D. 1990. Cover use and predator-related mortality in song and savannah sparrows. Auk 107:775-778.

Whittingham, M. J., and K. L. Evans. 2004. The effects of habitat structure on predation risk of birds in agricultural landscapes. Ibis $146: 210-220$.

\section{References Cited Only in the Online Appendixes}

Cassey, P., J. G. Ewen, T. M. Blackburn, M. E. Hauber, M. Vorobyev, and N. J. Marshall. 2008. Eggshell colour does not predict measures of maternal investment in eggs of Turdus thrushes. Naturwissenschaften 95:713-721, doi:10.1007/s00114-008-0376-x.

Cuthill, I. C., E. Hiby, and E. Lloyd. 2006. The predation costs of symmetrical cryptic coloration. Proceedings of the Roval Society B 273:1267-1271.

Endler, J. A., and P. W. Mielke Jr. 2005. Comparing entire color patterns as birds see them. Biological Journal of the Linnean Society 86:405-431.

Hart, N. S. 2001. Variations in cone photoreceptor abundance and the visual ecology of birds. Journal of Comparative Physiology A 187:685-697, doi:10.1007/s00359-001-0240-3.

Olsson, P., O. Lind, and A. Kelber. 2017. Chromatic and achromatic vision: parameter choice and limitations for reliable model predictions. Behavioral Ecology 29:273-282, doi:10.1093/beheco/arx133.

Siddiqi, A., T. W. Cronin, E. R. Loew, M. Vorobyev, and K. Summers. 2004. Interspecific and intraspecific views of color signals in the strawberry poison frog Dendrobates pumilio. Journal of Experimental Biology 207:2471-2485, doi:10.1242/jeb.01047.

Vorobyev, M., D. Osorio, A. T. D. Bennett, N. J. Marshall, and I. C. Cuthill. 1998. Tetrachromacy, oil droplets and bird plumage colours. Journal of Comparative Physiology A 183:621-633, doi:10.1007 /s003590050286.
Associate Editor: Christina Riehl Editor: Daniel I. Bolnick 